\title{
Evolution and Comparison of Electron Sources
}

Doug Rathkey, FEI Company

Over the years, we've seen major developments in electron source technologies in response to the demands for better performance. This article presents a brief overview of the cathode technologies in use today.

Two types of electron sources are used in commercially available scanning electron microscopes (SEMs), transmission electron microscopes (TEMs), scanning Auger microprobes, and electron beam lithography systems: thermionic and field emission electron cathodes. Thermionic cathodes release electrons from the cathode material when they are heated while field emission cathodes rely on a high electric field to draw electrons from the cathode material

\section{Thermionic Cathodes}

Tungsten filaments, lanthanum hexaboride ( $\left.\mathrm{LaB}_{6}\right)$ cathodes, and cerium hexaboride ( $\mathrm{Ce}_{6}$ ) cathodes are the three commonly used thermionic electron cathodes. Tungsten filaments were one of the first electron sources developed for SEMs and TEMs. They have a high work function (about $4.5 \mathrm{eV}$ ), meaning they require a large amount of heat to emit a given amount of electrons. Tungsten filaments also have low vacuum requirements and short lifetimes; however, they are relatively inexpensive, which makes them attractive for use in systems with multiple users or poor vacuums.

LaB6 cathodes were developed to fulfill the need for electron sources with higher brightness than tungsten. LaB6 cathodes are more efficient because they have a lower work function (about $2.6-2.7 \mathrm{eV}$ ) than tungsten and, therefore, can operate at lower temperatures with resulting longer lifetimes.

$\mathrm{CeB}_{6}$ themionic cathodes were introduced by $\mathrm{FEI}$ Company in 1992 as an alternative to $\mathrm{LaB}$. The $\mathrm{CeB}_{6}$ cathode is a direct substitute for LaBo and requires no instrument modifications. Experimental data shows that $\mathrm{CeB} 6$ evaporates $30-75 \%$ slower than $\mathrm{LaB} 6$, which means even longer operating lifetimes. $\mathrm{CeB}_{6}$ cathodes reach stable operation more quickly upon initial heating and have better resistance to contamination.

\section{Field Emission Cathodes}

Field emission cathodes were developed to provide extremely high-resolution, high-brightness SEM images at lower beam voltages than thermionic cathodes. Cold field emission cathodes are made from $\langle 310\rangle,\langle 111\rangle$ or slightly oxidized $\langle 100\rangle$ oriented tungsten wire with tip radii of $\langle 0.1 \mu$ m. Cold field emission cathodes operate at room temperature, and their electon emission is less damaging to biological and semiconductor specimens because their high source brightness permits low beam voltage operation with good resolution. Low beam voltages do not cause as much damage to specimens.

Schottky emission cathodes are something of a hybrid between field emission cathodes and thermionic emission cathodes. Best described as thermally-assisted field emission cathodes, Schottky emission cathodes were developed to overcome the drawbacks of cold field emission, namely high flicker noise $(4-6 \%)$ and strict vacuum requirements. A Schottky cathode consists of a ZrOW $\angle 100>$ electron emitter that is operated at $1800 \mathrm{~K}$ under somewhat relaxed vacuum requirements. Schottky electon emission is characterized by a low energy spread and extraordinarily high angular intensity, which permits focusing an extremely high current beam into an extremely small diameter. Schottky emission brightness is comparable to that of cold field emission, which allows high-resolution, low beam voltage operation.

\section{Development Continues}

Research on new electron source technology continues as users demand better per-performance from their cathodes; however, today's challenge for electron source manufacturers focuses more on the implementation of existing technologies in commercial instruments than on developing new source technologies.

\section{About FEl Company}

FEI Company is the world's foremost source of advanced technology products based on field emission technology. These products make possible the high-intensity, submicron ion and electron beams required in today's manometer-scale technology and VLSI/ULSI semiconductor fabrication and analysis. Applications include electron and ion beam microscopy, surface analysis, microcrosssectioning, microlithography, and microcircuit failure analysis and repair.

Since 1971, FEI has progressed from supplying single-crystal materials for electron sources - to producing the complete electron and ion sources - to developing the high-intensity, small beam diameter ion and electron beam columns with which the sources operate - and finally, to incorporating the column technology into a complete focused ion beam milling system for failure analysis and micromachining.

\begin{tabular}{|c|c|c|c|c|c|}
\hline & $\begin{array}{l}\text { Tungsten } \\
\text { Filaments } \\
\end{array}$ & $\mathrm{LaB}_{6}$ & $\mathrm{CeB}_{6}$ & $\begin{array}{l}\text { Cold field } \\
\text { emission }\end{array}$ & $\begin{array}{l}\text { Schottky } \\
\text { emission }\end{array}$ \\
\hline $\begin{array}{l}\text { Angular } \\
\text { current } \\
\text { intensity }\end{array}$ & $\mathrm{N} / \mathrm{A}$ & N/A & $\mathrm{N} / \mathrm{A}$ & $<0.1 \mathrm{~mA} / \mathrm{sr}$ & $0,1.1 .0 \mathrm{~mA} / \mathrm{sr}$ \\
\hline Brightness & $10^{6}{\mathrm{~A} / \mathrm{Cm}^{2}-5 \mathrm{~S}}^{2}$ & $10^{7} \mathrm{~A} / \mathrm{cm}^{2}-\mathrm{sr}$ & $10^{7} \mathrm{~A} / \mathrm{cm}^{2}-\mathrm{sr}$ & $10^{9}{\mathrm{~A} / \mathrm{cm}^{2}-\mathrm{sr}}^{2}$ & $5 \times 10^{8} \mathrm{~A} / \mathrm{cm}^{2}=\mathrm{sr}$ \\
\hline $\begin{array}{l}\text { Emitting } \\
\text { surface area }\end{array}$ & $\gg 1 \mu m^{2}$ & $\gg 1 \mu m^{2}$ & $\gg 1 \mu \mathrm{m}^{2}$ & $0.03 \mu \mathrm{m}^{2}$ & $>0.3 \mu \mathrm{m}^{2}$ \\
\hline $\begin{array}{l}\text { Virtual source } \\
\text { or crossover } \\
\text { diameter }\end{array}$ & $>10^{4} \mathrm{~nm}$ & $10^{4} \mathrm{~nm}$ & $10^{4} \mathrm{~nm}$ & $3 \mathrm{~nm}$ & $15 \mathrm{~nm}$ \\
\hline $\begin{array}{l}\text { Energy } \\
\text { spread }\end{array}$ & $1.0 \mathrm{eV}$ & $1.0 \mathrm{eV}$ & $1.0 \mathrm{eV}$ & $0.2-0.3 \mathrm{eV}$ & $0.3-1.0 \mathrm{eV}$ \\
\hline $\begin{array}{l}\text { Evaporation } \\
\text { rate }\end{array}$ & N/A & $2.9 \times 10^{-9} \mathrm{~g} / \mathrm{cm}^{2} \mathrm{sec}$ & $2.1 \times 10^{-9} \mathrm{~g} / \mathrm{cm}^{2} \mathrm{sec}$ & N/A & $\mathrm{N} / \mathrm{A}$ \\
\hline $\begin{array}{l}\text { Operating } \\
\text { vacuum }\end{array}$ & $10^{-5}$ tor & $10^{-7}$ torr & $10^{-7}$ tors & $10^{-10}$ torr & $10^{-9}$ torr \\
\hline $\begin{array}{l}\text { Short-term } \\
\text { beam current } \\
\text { stability }\end{array}$ & $<1 \%$ RMS & $<1 \%$ RMS & $<1 \%$ RMS & $4-6 \%$ RMS & $<1 \%$ RMS \\
\hline Standard cost & $\$ 20$ & $\$ 500-\$ 2000$ & $\$ 850$ & $\$ 500-\$ 2000$ & $\$ 1000-\$ 1500$ \\
\hline $\begin{array}{l}\text { Tip flashing } \\
\text { required? }\end{array}$ & No & No & No & Yes & No \\
\hline $\begin{array}{l}\text { Typical } \\
\text { service life }\end{array}$ & 100 hours & 1,000 hours & $>1,500$ hours & $2,000-10,000$ hours & $\begin{array}{l}5,000-10,000 \\
\text { hours }\end{array}$ \\
\hline $\begin{array}{l}\text { Work } \\
\text { function }\end{array}$ & $4.5 \mathrm{eV}$ & $2.6 \mathrm{eV}$ & $2.4 \mathrm{eV}$ & $4.5 \mathrm{eV}$ & $2.8 \mathrm{eV}$ \\
\hline
\end{tabular}

The above chart compares tungsten filaments, $\mathrm{LaB}_{6}$ cathodes, $\mathrm{CEB}_{6}$ cathodes, cold field emission cathodes, and Schottky emission cathodes 


\section{NanoScope scanning Probe Microscopes}

\section{We Have Science Covered}

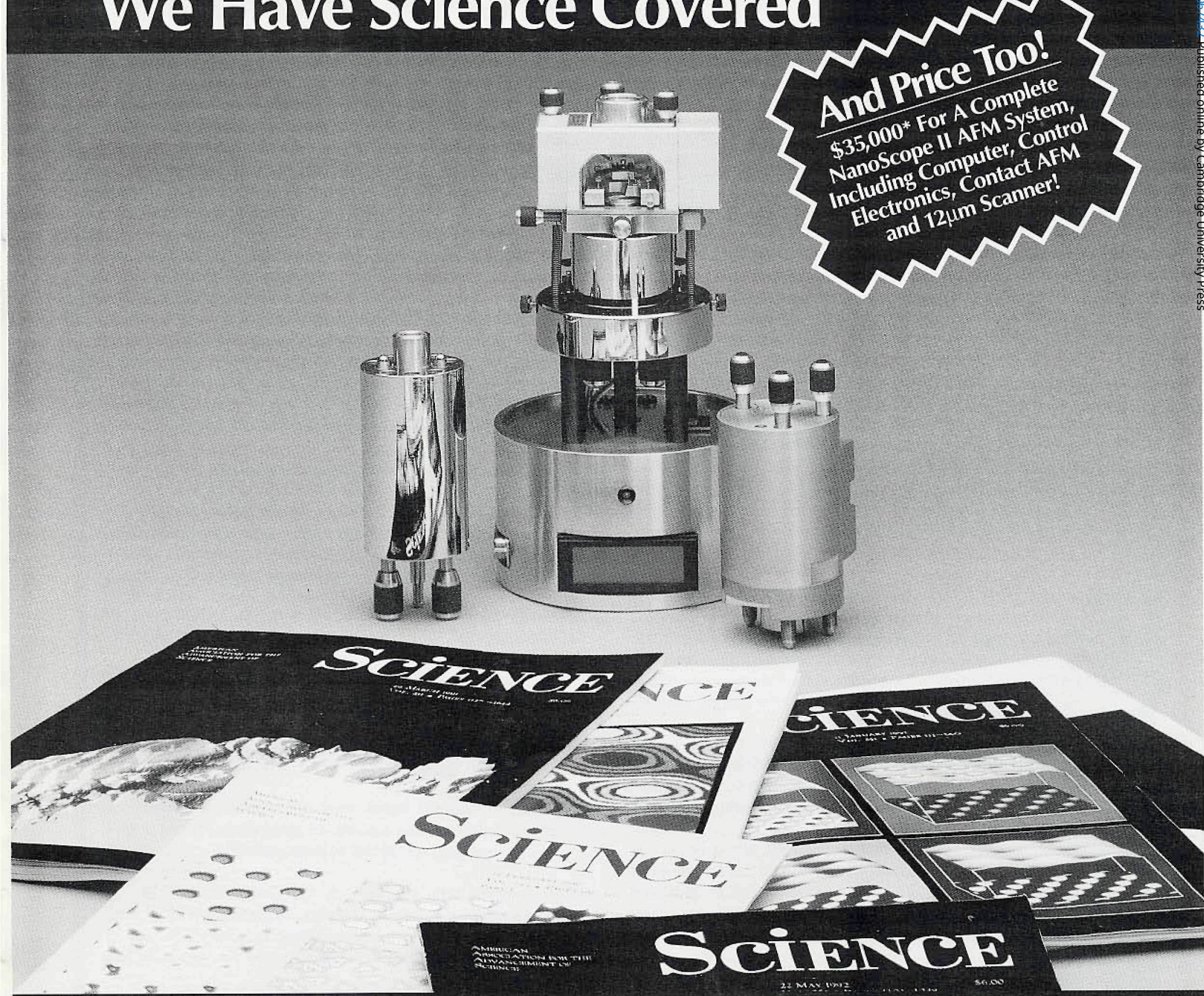

Nore scientific publications have been proother SPM. While the NanoScope III is now the state of the art, as well as the focus of our current engineering efforts, the NanoScope II is still one of the most useful SPM systems available.
Want to save money now, but are worried about keeping up with the latest technology? When you are ready for a NanoScope III we will be happy to offer you an upgrade at a price that will protect your initial investment.

Call today to take advantage of this great price. 